\title{
Evaluation of the Prevalence of Maxillary Sinuses Abnormalities through Spiral Computed Tomography (CT)
}

\author{
João Paulo Nunes Drumond ${ }^{1}$ \\ Wilson Roberto Sendyk ${ }^{1}$ \\ ${ }^{1}$ Department of Oral Implantology, Universidade de Santo Amaro \\ Ringgold Standard Institution, São Paulo, SP, Brazil \\ 2 Department of Radiology and Diagnostic Imaging, Hospital \\ Heliopolis Ringgold Standard Institution, São Paulo, São Paulo, Brazil \\ ${ }^{3}$ Department of Statistics and Health Sciences, Universidade de Santo \\ Amaro Ringgold Standard Institution, São Paulo, São Paulo, Brazil \\ ${ }^{4}$ Department of Otolaryngology Head and Neck Surgery, Universidade \\ Federal de Sao Paulo Ringgold Standard Institution, São Paulo, \\ São Paulo, Brazil
}

\begin{abstract}
Address for correspondence João Paulo Nunes Drumond, DMD, MDSc, Department of Oral Implantology, Universidade de Santo Amaro, Medical School, Street Prof. Enéas de Siqueira Neto, 340 Jardim das Imbuias, São Paulo, SP 04829-300, Brazil (e-mail: jpnd@uai.com.br).
\end{abstract}

Int Arch Otorhinolaryngol 2017;21:126-133.

\begin{abstract}
Introduction Maxillary sinus disease is common and numerous disorders can affect this anatomical area. Abnormalities can be classified as: non-neoplastic, neoplastic benign, and neoplastic malignant.

Objective Evaluate through CT the prevalence of diseases in maxillary sinuses, using the Radiology Department's database of a hospital in São Paulo city.

Methods The sample consisted of 762 facial CT scans that we divided into three groups: Group A (12-19 years old); Group B (20-49 years old); Group C (above 50 years old); and male or female. We considered the following pathological processes: I - Mucoperiosteal Thickening; II - Chronic Sinusitis; III - Chronic Odontogenic Sinusitis; IV - Rhinosinusitis; V - Polypoid Lesions; VI - Bone Lesions; VII Neoplasms; VIII - Antrolith; IX - Foreign Bodies; X - Oroantral Fistula.

Results Our study found that 305 exams (40.02\%) were normal and 457 exams (59.97\%) were abnormal. We found the following disease frequencies: focal mucoperiosteal thickening (21.25\%); polypoid lesions (10.76\%); chronic sinusitis (7.48\%); chronic odontogenic sinusitis (2.29\%); neoplasms (2.03\%); rhinosinusitis (1.77\%); bone lesions, foreign bodies and oroantral fistula in $0.65 \% ; 0.13 \%$ and $0.06 \%$ respectively. There was

Keywords

- maxillary sinus

- spiral computed tomography

- diagnostic imaging

- otolaryngology

- epidemiology no significant difference between male and female, and Groups A, B, or C when relating the frequencies of abnormalities found. There was no significant difference between male and female and the age group for the side of the altered maxillary sinus.

Conclusion We observed a high prevalence of sinus maxillary diseases. Mucoperiosteal thickening; acute, chronic, and odontogenic sinusitis; polypoid lesions and neoplasms have high prevalence in maxillary sinuses. Thus, facial CT exam was effective for the evaluation of diseases in maxillary sinuses.
\end{abstract}

received

May 19, 2016

accepted

August 30, 2016

published online

December 27, 2016
DOI http://dx.doi.org/

10.1055/s-0036-1593834. ISSN 1809-9777.
Copyright @ 2017 by Thieme-Revinter

Publicações Ltda, Rio de Janeiro, Brazil
License terms

(c) (i) $\ominus \$$ 


\section{Introduction}

The facial region is formed in general, by oral cavity, jaw bones, nose and paranasal sinuses. Due to the wide anatomic proximity between the facial structures, diseases in one component can easily affect others. ${ }^{1}$ The maxillary sinuses are the largest of all paranasal sinuses and are located bilaterally within the maxilla bone, assuming a pyramidal shape. ${ }^{2}$

The maxillary sinus disease is common and numerous disorders can affect this anatomical area. Abnormalities can be grouped as: non-neoplastic, neoplastic benign, and neoplastic malignant. Inflammatory processes, infections, cysts, polyps, and mucoceles are examples of non-neoplastic lesions. Papilloma, fibro-osseous, and mesenchymal tumors are benign neoplasms. The Squamous Cell Carcinoma, adenocystic carcinoma, adenocarcinoma, and sarcomas are some types of malignant tumors that affect the maxillary sinus. ${ }^{3}$

Maxillary sinus diseases can be classified according to their nature as: congenital (aplasia and hypoplasia); neoplastic (benign or malignant); dental conditions (benign dental tumor, odontogenic cyst or periapical inflammatory lesion); bone injury (ossifying fibroma, Fibrous Dysplasia, and Paget's Disease); traumatic bone injury; iatrogenic (related to previous surgical procedures); inflammatory (mucosal thickening, opacification, polyp, mucous retention cyst, antrolith); systemic; and silent sinus syndrome. ${ }^{4,5}$

Mucosal thickening is an inflammatory reaction with hyperplasia of the mucous lining of the maxillary sinus. ${ }^{2}$ This condition may result from harmful actions caused by trauma, infections, chemical agents, foreign body reaction, neoplasm, or airway conditions such as allergies, rhinitis, or asthma. ${ }^{6}$ The prevalence of allergic rhinitis in the world population is around $10.25 \%$. Continuous exposure to inhaled allergens produces a chronic inflammation in the nasal-sinus mucosa, identified as mucosal thickening on Computed Tomography (CT). ${ }^{8}$

Sinusitis is the most common disease of the paranasal sinuses. Forms of acute or chronic presentation when hassle, do not require diagnostic imaging; but when the symptoms are recurrent or refractory, research with imaging is needed for a better diagnosis. ${ }^{9}$ There is one distinction between acute and chronic sinusitis. In acute sinusitis, liquid or fluid levels inside the maxillary sinus are isolated; but in chronic sinusitis, there is a thickening of the bone sinus wall. ${ }^{10}$ The odontogenic maxillary sinusitis differs from rhinogenic for its pathophysiology, microbiology, and treatment. The odontogenic maxillary sinusitis is $10 \%$ to $40 \%$ of all maxillary sinusitis, and its incidence may be increasing. ${ }^{11}$

Mucosal cysts are a common incidental finding on imaging studies, with an incidence between 12.4 and $35.6 \%{ }^{12}$ They are typically spherical opacities on CT scanning, and are not associated with symptoms of chronic rhinosinusitis. ${ }^{3}$ Mucocele are pseudocysts expansive formations of the paranasal sinuses, whose wall consists of a modified sinus mucosa and the presence of cystic aseptic liquid inside, generally thick and viscous, and may be infected and became a mucopyocele. ${ }^{13}$ The accumulation of fluid increases intrasinusal pressure, resulting in expansion and bone destruction. Nasal polyps develop from the thickening of chronically inflamed mucosa, causing irregular mucosal folds. The polyposis can develop singly or in multiple forms within the maxillary sinus. ${ }^{6}$

The maxillary sinus carcinoma is uncommon, representing $3 \%$ of head and neck carcinoma and $80 \%$ of tumors of the paranasal sinuses. Most tumors that affect the maxillary sinus have epithelial origin, and Squamous Cell Carcinomas account for $\sim 85 \%$ of all sinus malignancies, followed by adenocystic carcinoma, with 5-15\% frequency. These tumors, when small, are misdiagnosed as chronic sinusitis or polyps. In $40-60 \%$ of cases we observed facial asymmetry, bulging of the oral cavity, and invasion into the nasal cavity. In a more advanced stage, maxillary sinus carcinomas reach the pterygopalatine fossa, pterygoid muscles, orbital fissure, cavernous sinus, skull base structures, and central nervous system. This type of injury has very poor prognosis due to late detection and difficult complete surgical resection, with 5-year survival rate ranging from $20-40 \%{ }^{14}$

In our study, we observed the prevalence of pathological findings in maxillary sinuses in a sample of 1029 Cone Beam CT (CBCT) exams. Results from 450 patients (43.7\%) showed normal images. We noted mucosal thickening in 392 patients (38.1\%); partial sinus opacification was present in 123 patients (11.9\%); total opacification was present in 73 patients (6.9\%); and 67 cases $(6.4 \%)$ had polypoid formations. ${ }^{15}$

We studied a sample of 513 CBCT scans obtained for orthodontic diagnosis and treatment planning. We observed mucosal thickening in 258 sinuses (25.1\%), detected pseudocysts in 59 sinuses (5.75\%), and 26 (5.1\%) sinuses presented severe opacification. Gender was a significant predictor of pseudocysts, with male subjects showing a $196.3 \%$ higher relative risk of this pathology. Age was a significant predictor of mucosal thickening, with subjects aged 41 - 60 years showing a $401 \%$ higher odds ratio than those aged 12 - 18 years. ${ }^{16}$

Through CBCT, we evaluated 1406 maxillary sinus and identified abnormalities. We diagnosed diseases in $68.2 \%$ of cases. Mucosal thickening was the most prevalent abnormality (66\%), followed by polypoid lesions (10.1\%), opacification (7.8\%), antrolith (3.2\%), oroantral communication (2.2\%), bone lesions (1.8\%), neoplasms, and benign dental tumors in $1.3 \%$.There was a significant difference between the genders, showing a greater occurrence of sinus abnormalities in males ( $p<0.001)$. We observed no difference in the occurrence of abnormalities with regards to the age groups $(\mathrm{p}>0.05){ }^{17}$

A retrospective study, 34 patients eligible for dental implant surgery underwent imaging of the maxilla by CBCT. The mucosal thickening was found in 33 maxillary sinuses, representing a prevalence of $48.52 \%$ and total opacification was observed in 2 maxillary sinuses, with a prevalence of $2.94 \%{ }^{18}$

Using CT or CBCT, we evaluated 275 patients for the prevalence of diseases in the maxillary sinuses. Overall, $54.9 \%$ scans were classified as healthy, and $45.1 \%$ scans were classified as exhibiting sinus pathology. Men were more likely to exhibit pathology compared with females $(p<0.01)$. However, age did not seem to have any relation on the prevalence of sinus pathology. Mucosal thickening was observed in $56.5 \%$ of maxillary sinuses, $28.2 \%$ had polypoid 
formations, $8.9 \%$ partial opacification, and $6.5 \%$ complete opacification. $^{19}$

In another study, two observers assessed 402 maxillary sinuses via CBCT searching incidental pathological findings. The overall prevalence of diseases was $59.7 \%$, and mucosal thickening was present in $35.1 \%$ of the maxillary sinuses, followed by opacification (16.6\%), polypoid formations (7.2\%), and other findings in $0.7 \%{ }^{20}$

A retrospective cohort study based on CT scans analyzed 504 patients who were being treated in an oral surgery clinic. The authors evaluated the relationship between etiological dental factors with imaging changes in maxillary sinuses, specifically mucosal thickening, air-fluid levels or opacification. They reported that $32.40 \%$ presented maxillary sinus without pathologic changes and without any etiological factor associated; $29.00 \%$ showed presence of factors and imaging changes; $20.60 \%$ had only imaging changes in the maxillary sinus; and $18.00 \%$ had only etiological factors and normal maxillary sinuses. ${ }^{21}$

This study evaluated the prevalence of all maxillary sinuses disease groups, through images obtained by Facial CT scans in a public hospital database, common interest injuries among dental specialties, otolaryngology, and head and neck surgery. Due to the clinical significance of abnormalities in maxillary sinus and its high frequency, knowledge of the prevalence and characterization by imaging in a given population can be very useful for a more accurate diagnosis and subsequent indication for treatment with greater safety and efficacy.

\section{Method}

In this cross-sectional study, we conducted a quantitative assessment, with images analysis from the database of the Department of Radiology and Diagnostic Imaging of a public referral hospital - in São Paulo city, Brazil. The Data Transfer Agreement and Co-Participant Declaration were indispensable for the development of this research. The Research Ethics Committee previously approved the research project attached to the documents above, under CAE 42728815.5.0000.5449 and number 1113368 of 05/07/2015.

Selection of patients: the sample was composed of 762 Facial CT scans, performed in a hospital setting from February 2012 to February 2014, requested by doctors and dentists. The sample included patients of both sexes, aged over 12 years and having performed Facial CT scan for any indication. The sample excluded: patients younger than 12 years, due to their incomplete formation of the maxillary sinuses; patients with a history of surgery in maxillary sinus; exams whose patient identification data were incomplete, or when the maxillary sinuses were not completely displayed on the exam.

To assess the prevalence of pathological processes varying according to age and sex, we divided the examinations into 3 groups according to the following age groups: Group A (aged 12-19 years); Group B (aged 20 to 49 years); Group C (age above 50 years); and male or female.

Acquisition of images: we obtained the images in a unit of Spiral Computed Tomography, model Siemens Somatom Emo- tion (Siemens AG, Forchheim, Germany). The images were processed and evaluated in EPACS WORKSTATION (EPEOPLE Technology Solutions, São Paulo, Brazil) version 5.13.10.17.

Image interpretation: the images were dynamically manipulated in axial and coronal planes. A resident doctor in Radiology/Diagnostic Imaging and an Oral \& Maxillofacial surgeon performed the analyses simultaneously; respectively calibrated and fixed throughout the study. The Radiological Reports would undergo consultation for verifying purposes in case of disagreement among examiners.

Data collection: we prepared a specific Data Collection Form. The evaluation process was done in two stages. In the first stage, we noted general demographic data, such as age and gender, or the presence or absence of sinus disease, and later marked the Data Collection Form as (1) Abnormal and (2) Normal. If abnormal, we also noted the affected side as (D) Right, (E) Left, or (DE) Bilateral. In the second stage, we only selected the exams classified as (1) Abnormal by at least one examiner, and the disease was classified according to the criteria established.

Rating: we considered the following pathological processes: 1- Mucosal Thickening (soft thickening, mild, or focal thickness greater than $2 \mathrm{~mm}$ ); 2 - Chronic Sinusitis (partial or complete opacification; or round mucosal thickening); 3 Odontogenic Sinusitis; 4 - Acute Rhinosinusitis; 5 - Polypoid Lesions (mucous retention cyst, polyp, or mucocele); 6 - Bone Injury (bone cysts, Fibrous Dysplasia, fractures, Paget's Disease); 7 - Neoplasms (benign or malignant); 8 - Antrolith; 9 Foreign Bodies; 10 - Oroantral Fistula.

According to location within the maxillary sinus, we classified the sinus abnormalities as follows: (A) Anterior, (P) Posterior, (I) Inferior, (S) Superior, (M) Medial, (L) Lateral and, with combined locations: (C) Combined.

Verification of data and statistics: we determined data through manual counting, organized in tabs, and presented in the form of tables and graphs for demonstration of their frequency and prevalence of results, thus fulfilling the objectives of the study. The results underwent statistical analysis by Chi-Square $\chi^{2}$. The objective of the statistical analysis was to correlate the age and gender of patients with the frequency of sinus findings and its unilateral or bilateral occurrence. We applied the same test to analyze comparatively the frequencies of the three most prevalent alterations in this study with results observed in studies with similar methodology over the last five years. In all tests, the level of significance was set at $5 \%(p<0.05)$.

\section{Result}

Among the 762 cases evaluated by Facial CT scans, 475 (62.33\%) were male and 287 (37.66\%) were female. Group A included 29 exams (3.80\%); Group B included 253 (33.20\%), and $480(63.00 \%)$ were at Group C. Ages ranged from 12 to 95 years. 305 exams (40.02\%) were normal, and 457 exams (59.97\%) were abnormal. Of the 457 abnormal exams, 139 (30.41\%) had disease in the right maxillary sinus only; 128 (28.01\%) in the left maxillary sinus only; and 190 (41.57\%) had the disease in both sides. 
Table 1 Absolute prevalence of maxillary sinus findings

\begin{tabular}{|l|l|l|}
\hline Rating & N & $\begin{array}{l}\text { (\%) All Maxillary } \\
\text { Sinuses }\end{array}$ \\
\hline Mucosal Thickening & 324 & 21.25 \\
\hline Chronic Sinusitis & 114 & 7.48 \\
\hline Odontogenic Sinusitis & 35 & 2.29 \\
\hline Acute Rhinosinusitis & 27 & 1.77 \\
\hline Polypoid Lesions & 164 & 10.76 \\
\hline Bone Injury & 10 & 0.65 \\
\hline Neoplasms & 31 & 2.03 \\
\hline Foreign Bodies & 2 & 0.13 \\
\hline Antrolith & 0 & 0.00 \\
\hline Oroantral Fistula & 1 & 0.06 \\
\hline
\end{tabular}

We found the following diseases frequencies: focal mucosal thickening in $21.25 \%$; polypoid lesions in $10.76 \%$; chronic sinusitis in $7.48 \% ; 2.29 \%$ of maxillary sinuses had chronic odontogenic sinusitis; neoplasms were present in $2.03 \%$; acute rhinosinusitis in $1.77 \%$; bone injury and foreign bodies in $0.65 \%$ and $0.13 \%$ respectively; and oroantral fistula in $0.06 \%$ (-Table 1). The frequency of the respective anatomical locations inside the maxillary sinus is shown in - Table 2. - Figs. 1-8 show some examples of the diseases detected.

The Chi-Square Test $\chi^{2}$ was applied to verify the proposed relations. Regardless of gender and age group, we observed that the frequency of abnormalities was $59.97 \%\left(\chi^{2}=1.82\right.$; $p=0.3942 ; \mathrm{IL}=56.50 \%$ and $\mathrm{SL}=63.44 \%$ ) (-Table 3 ). There was no significant difference between male and female $\left(\chi^{2}=7.32\right.$ and $\left.p=0.3961\right)$ ( - Table 4), and Groups A, B, or $\mathrm{C}\left(\chi^{2}=16.08 ; p=0.3088\right)$ (-Table 5); when comparing the frequencies of abnormalities found. There was no significant difference between male and female and the age group for the side of the altered maxillary sinus $\left(\chi^{2}=1.65\right.$ and $p=0.4381$; $\chi^{2}=4.63$ and $p=0.3280$ ) (-Tables 6 and 7).

\section{Discussion}

In this study, we found an overall prevalence of pathological findings in 457 patients, which prevalence was $59.97 \%$. Observing the overall of maxillary sinuses, 647 showed these abnormalities, representing a prevalence of $42.45 \%$. Other results were observed in previous studies, whose authors reported the following total prevalence of maxillary sinuses diseases: 56.3\%, 50.3\%, 68.2\%, 45.1\%, 59.7\%, and 49.6\%. ${ }^{15-17,19-21}$

Importantly, the data obtained in this study are correlated to a population already suspected of having an abnormality in the maxillary sinuses. Patients to undergo the facial diagnostic imaging were under medical or dental care, or at least had symptoms that could justify the examination in hospital.

Some authors cite the mucosal thickening as the most frequent finding in maxillary sinus, with prevalence ranging from $38.1 \%$; $25.1 \%, 66 \%, 48.52 \%$; $56.5 \%$, and $35.1 \%$. ${ }^{15-20}$ In our
Table 2 Frequency of anatomical location

\begin{tabular}{|l|l|l|}
\hline Sinus Surface & N & $\begin{array}{l}\text { (\%) Abnormal Maxillary } \\
\text { Sinuses }\end{array}$ \\
\hline Anterior & 9 & 1.40 \\
\hline Posterior & 8 & 1.24 \\
\hline Inferior & 157 & 24.26 \\
\hline Superior & 24 & 3.71 \\
\hline Medial & 41 & 6.33 \\
\hline Lateral & 37 & 5.72 \\
\hline Combined & 371 & 57.34 \\
\hline
\end{tabular}

study, the occurrence of mucosal thickening in 324 of 1524 maxillary sinuses evaluated, representing a prevalence of $21.25 \%$. Although the values we found were lower than those of the authors mentioned above, this condition was also the most frequent in our study. It is then possible that the epidemiological importance of this inflammatory finding is closely related to its variable etiology - traumatic, infectious, chemical, or allergic. Among these possible etiologies, there is allergic cause, taking into account the high incidence of allergic rhinitis in the general population as well as the fact that mucosal thickening is more common in individuals with allergic rhinitis.

Images classified as chronic sinusitis show round mucosal thickening, partial opacification, or complete opacification of the maxillary sinus. As for the images classified as acute rhinosinusitis, there are prominent fluid or liquid levels, indicative of the acute phase of this disease. Authors reported the following rates for acute or chronic sinusitis: $19.04 \%, 5.1 \%$, $7.8 \%, 15.4 \%, 2.94 \%$, and $16.6 \%{ }^{15-20}$ In our study, we found $7.48 \%$ prevalence of chronic sinusitis and $1.77 \%$ for acute sinusitis, a total of 141 of the 1524 maxillary sinuses evaluated, accumulating an overall prevalence of $9.25 \%$ for chronic and acute sinusitis, excluding odontogenic diseases.

We observed the occurrence of chronic odontogenic diseases in 35 of 1524 maxillary sinuses evaluated, resulting in a prevalence of $2.29 \%$. However, if we just consider the overall maxillary sinuses with suggestion of sinusitis (176), the amount occupied by dental origin corresponds to a value of $19.88 \%$; coinciding with the range of the aforementioned values. ${ }^{11}$ In a specific study to evaluate the presence of inflammatory processes related to dental factors, $29 \%$ of patients assessed had confirmed odontogenic sinusitis, also converging with the above values. ${ }^{21}$

The polypoid lesions described are represented by mucous cysts, pseudocysts, or mucoceles, sinus polyps, and antrochoanal polyps. These lesions are worth noting for epidemiological purposes in this study and other literature consulted. We observed the presence of polypoid lesions in 164 of the 1524 maxillary sinuses evaluated, indicating an overall prevalence of $10.76 \%$. Other authors cite the following rates: $5.9 \%$, $5.75 \%, 10.1 \%, 28.2 \%$, and $7.2 \%{ }^{15-17,19,20}$

Maxillary sinuses may be affected by benign or malignant neoplasms worthy of great clinical relevance not by the high 


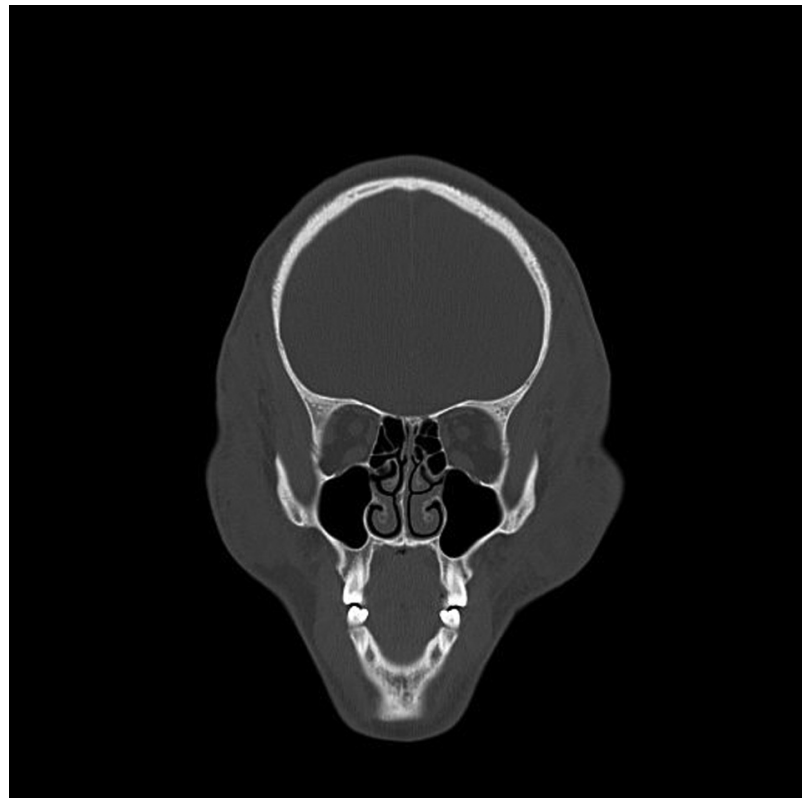

Fig. 1 Normal maxillary sinuses.

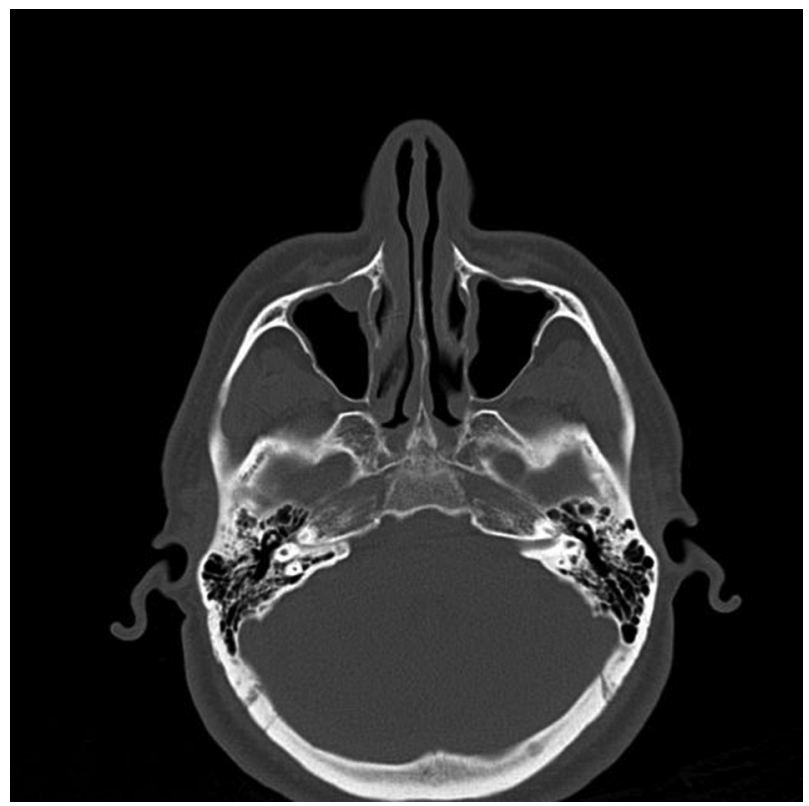

Fig. 2 Mucosal thickening.

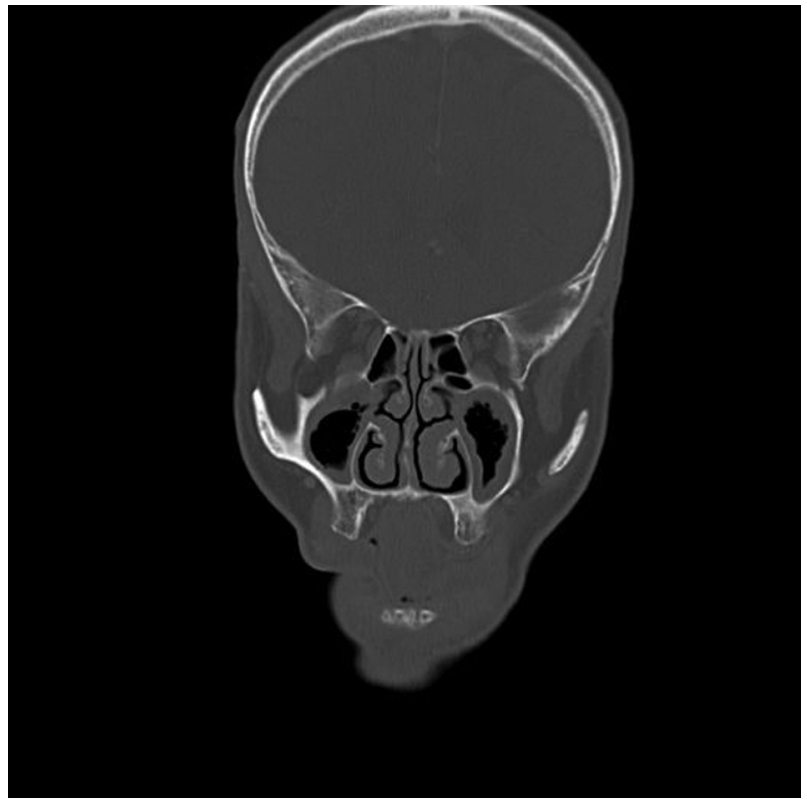

Fig. 3 Chronic sinusitis.

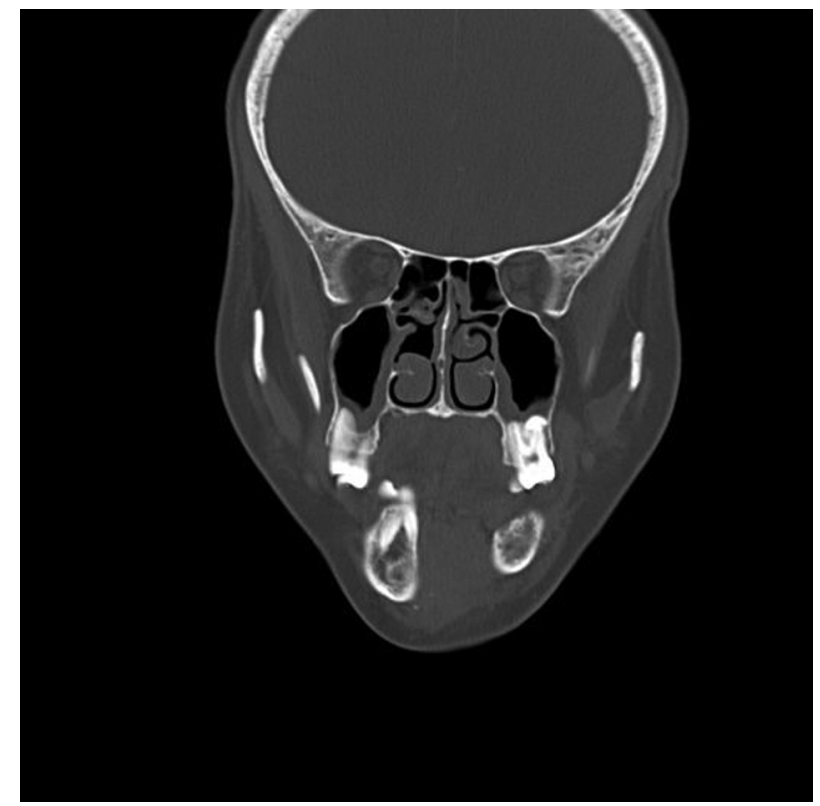

Fig. 4 Odontogenic sinusitis. 


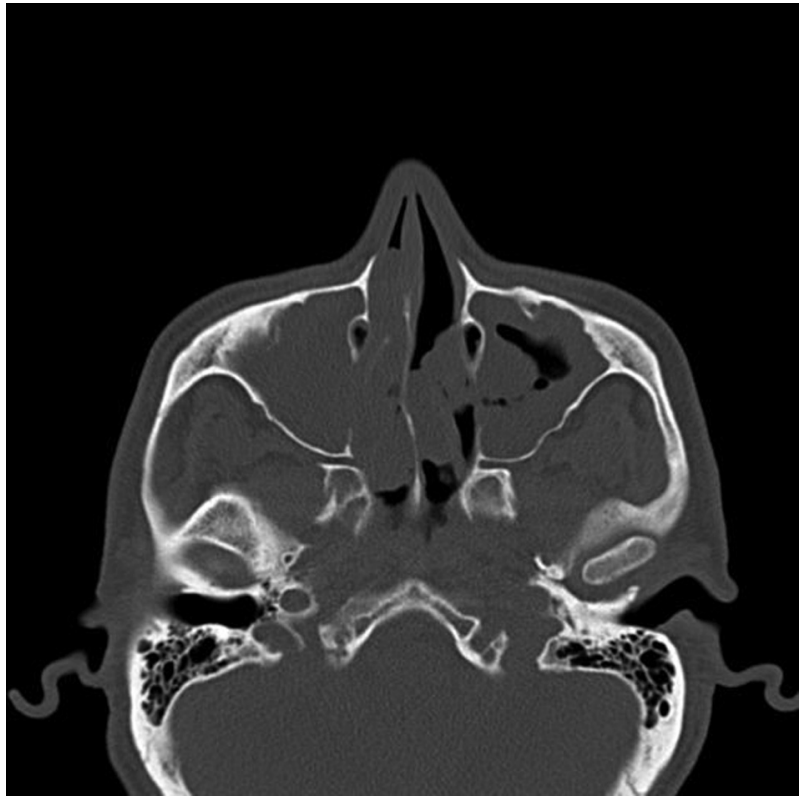

Fig. 5 Acute rhinosinusitis.

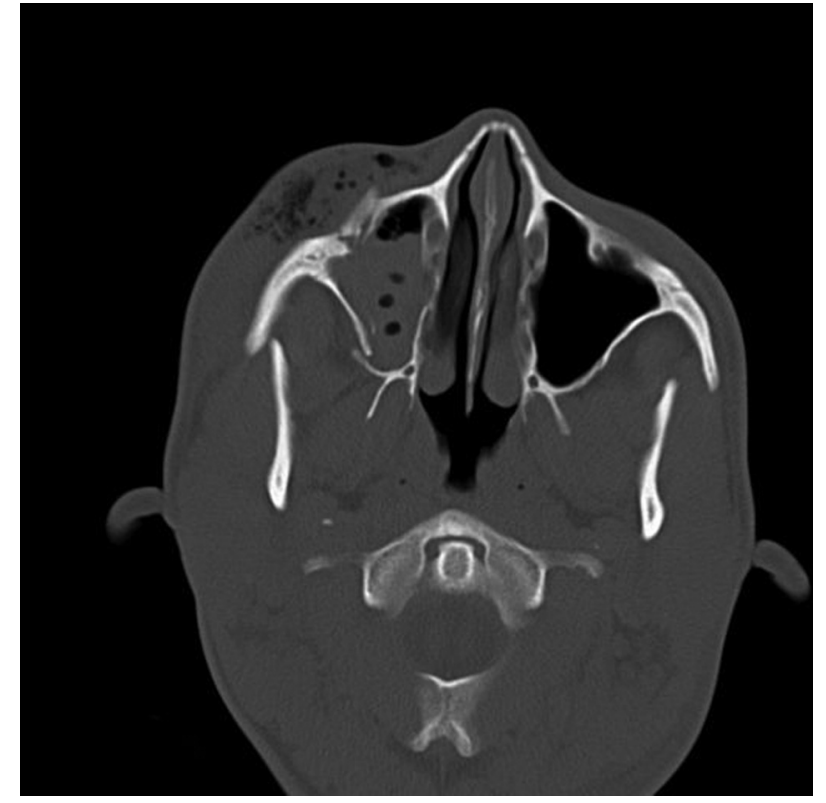

Fig. 7 Bone injury: middle facial fracture.

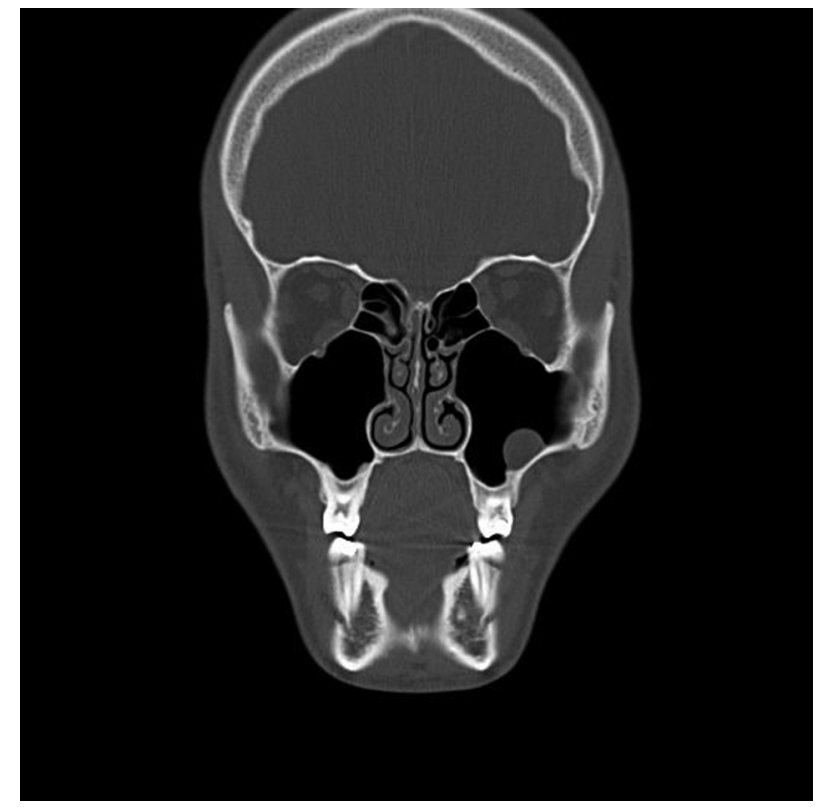

Fig. 6 Polypoid lesion.

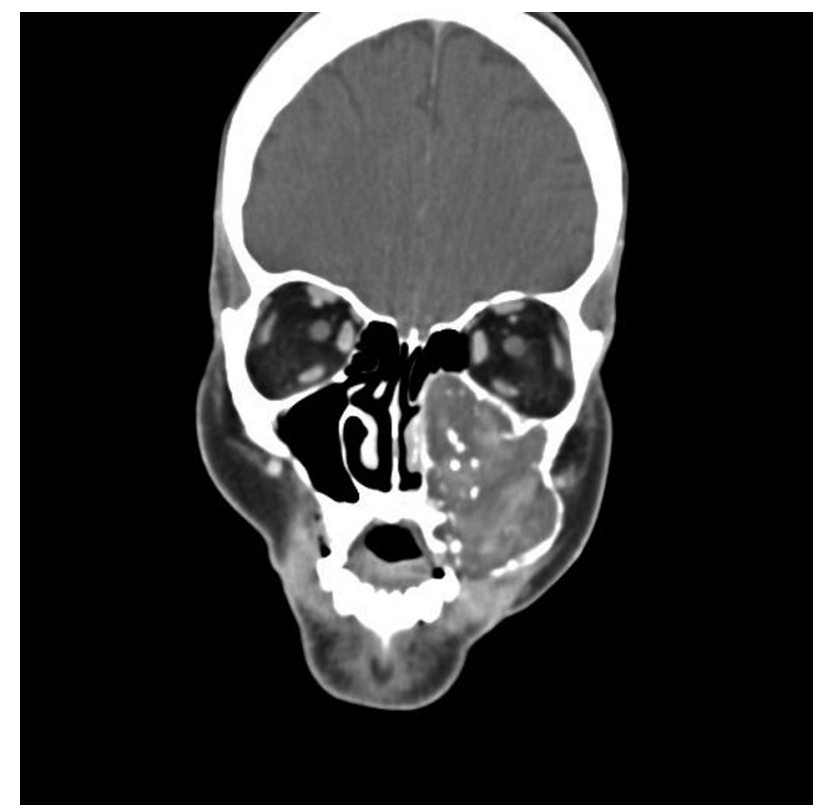

Fig. 8 Neoplasm. 
132 Prevalence of Maxillary Sinuses Abnormalities through Spiral CT Drumond et al.

Table 3 Frequency of abnormal maxillary sinuses: Group

\begin{tabular}{|l|l|l|l|l|}
\hline Group & Abnormal & Normal & Overall & $\begin{array}{l}\text { (\%) All } \\
\text { Abnormal }\end{array}$ \\
\hline A & 18 & 11 & 29 & 62.10 \\
\hline B & 160 & 93 & 253 & 63.20 \\
\hline C & 279 & 201 & 480 & 58.10 \\
\hline Overall & 457 & 305 & 762 & 59.97 \\
\hline
\end{tabular}

$\chi^{2}=1.86(p=0.3942)$.

Table 4 Frequency of maxillary sinus findings: Gender

\begin{tabular}{|l|l|l|}
\hline Rating & $\begin{array}{l}\text { Male } \\
\text { N (\%) }\end{array}$ & $\begin{array}{l}\text { Female } \\
\text { N (\%) }\end{array}$ \\
\hline Mucosal Thickening & $219(46.0)$ & $105(45.3)$ \\
\hline Chronic Sinusitis & $74(15.5)$ & $40(17.2)$ \\
\hline Odontogenic Sinusitis & $18(3.8)$ & $17(7.3)$ \\
\hline Acute Rhinosinusitis & $18(3.8)$ & $9(3.9)$ \\
\hline Polypoid Lesions & $117(24.6)$ & $47(20.3)$ \\
\hline Bone Injury & $7(1.5)$ & $3(1.3)$ \\
\hline Neoplasms & $22(4.6)$ & $9(3.9)$ \\
\hline Others & $1(0.2)$ & $2(0.9)$ \\
\hline Overall & $476(100)$ & $232(100)$ \\
\hline
\end{tabular}

$\chi^{2}=7.32(p=0.3961)$.

prevalence, but by the difficult diagnosis and the possibility of involvement of adjacent vital structures. This study showed benign or malignant neoplastic lesions in 31 maxillary sinus reviews, representing a prevalence of $2.03 \%$, similar to the rate found in other research. ${ }^{17}$ Neoplasm sinuses have important absolute prevalence, ranking fifth; even more than acute rhinosinusitis isolated; however, most attention is focused on the early diagnosis due to the severity of injuries and poor prognosis in cases of malignant lesions in advanced stages.

Based on such comparisons, we can consider mucosal thickening, sinus opacification processes (acute, chronic, or odontogenic sinusitis), and polypoid lesions as high prevalence diseases in maxillary sinuses $(21.25 \%, 11.54 \%$, and $10.76 \%$, even in CT scans performed in asymptomatic patients, constituting cases of incidental findings.
Table 5 Frequency of maxillary sinus findings: Group

\begin{tabular}{|l|l|l|l|}
\hline Rating & $\begin{array}{l}\text { Group A } \\
\text { N (\%) }\end{array}$ & $\begin{array}{l}\text { Group B } \\
\text { N (\%) }\end{array}$ & $\begin{array}{l}\text { Group C } \\
\text { N (\%) }\end{array}$ \\
\hline Mucosal Thickening & $11(36.7)$ & $105(40.4)$ & $208(49.8)$ \\
\hline Chronic Sinusitis & $3(10.0)$ & $46(17.7)$ & $65(15.6)$ \\
\hline Odontogenic Sinusitis & $1(3.3)$ & $16(6.2)$ & $18(4.3)$ \\
\hline Acute Rhinosinusitis & $3(10.0)$ & $12(4.6)$ & $12(2.9)$ \\
\hline Polypoid Lesions & $9(30.0)$ & $65(25.0)$ & $90(21.5)$ \\
\hline Bone Injury & $1(3.3)$ & $5(1.9)$ & $4(1.0)$ \\
\hline Neoplasms & $2(6.7)$ & $9(3.5)$ & $20(4.8)$ \\
\hline Others & $0(0.0)$ & $2(0.8)$ & $1(0.2)$ \\
\hline Overall & $\mathbf{3 0 ( 1 0 0 )}$ & $\mathbf{2 6 0 ( 1 0 0 )}$ & $\mathbf{4 1 8 ( 1 0 0 )}$ \\
\hline
\end{tabular}

$\chi^{2}=16.08(p=0.3088)$

Table 6 Diseased maxillary sinus: Gender

\begin{tabular}{|l|l|l|}
\hline Side & $\begin{array}{l}\text { Male } \\
\text { N (\%) }\end{array}$ & $\begin{array}{l}\text { Female } \\
\text { N (\%) }\end{array}$ \\
\hline Right & $97(31.8)$ & $42(27.6)$ \\
\hline Left & $80(26.2)$ & $48(31.6)$ \\
\hline Bilateral & $128(42.0)$ & $62(40.8)$ \\
\hline Overall & $305(100)$ & $152(100)$ \\
\hline
\end{tabular}

$\chi^{2}=1.65(p=0.4381)$.

- Table 8 shows the comparative study of the frequency of the three most prevalent sinus findings in this study compared with other studies published in the last five years. We observed statistically significant difference $(p<0.05)$ between the results, suggesting that the sample quality may have influenced the result. This survey was conducted in a hospital environment, as opposed to the others authors who collected data in outpatient basis (CBCT), presumably asymptomatic candidates in oral rehabilitation procedures.

Statistical analysis showed that there are no relations between patient gender and age, with regards to changes in frequency of sinus and the side affected. Another study found that men were more likely to have disease in the maxillary sinuses ( $p<0.01$ ), but the age of the patients did not constitute a factor of influence. ${ }^{19}$ According to another study, males

Table 7 Diseased maxillary sinus diseased: Group

\begin{tabular}{|l|l|l|l|}
\hline Side & $\begin{array}{l}\text { Group A } \\
\text { N (\%) }\end{array}$ & $\begin{array}{l}\text { Group B } \\
\text { N (\%) }\end{array}$ & $\begin{array}{l}\text { Group C } \\
\text { N (\%) }\end{array}$ \\
\hline Right & $6(33.33)$ & $40(25.0)$ & $93(33.33)$ \\
\hline Left & $3(16.66)$ & $48(30.0)$ & $77(27.60)$ \\
\hline Bilateral & $9(50.00)$ & $72(45.8)$ & $109(39.06)$ \\
\hline Overall & $18(100)$ & $160(100)$ & $279(100)$ \\
\hline
\end{tabular}

$\chi^{2}=4.63(p=0.3280)$. 
Table 8 Comparative study of frequency of three main findings

\begin{tabular}{|l|l|l|l|l|l|l|}
\hline $\begin{array}{l}\text { Study } \\
\text { Rating }\end{array}$ & $\begin{array}{l}\text { Drumond } \\
\text { N (\%) }\end{array}$ & $\begin{array}{l}\text { Raghav } \\
\text { N (\%) }\end{array}$ & $\begin{array}{l}\text { Manji } \\
\text { N (\%) }\end{array}$ & $\begin{array}{l}\text { Gracco } \\
\text { N (\%) }\end{array}$ & $\begin{array}{l}\text { Rege } \\
\text { N (\%) }\end{array}$ & $\begin{array}{l}\text { Ritter } \\
\text { N (\%) }\end{array}$ \\
\hline 1 & $324(48.8)$ & $141(59.5)$ & $70(56.4)$ & $252(74.7)$ & $928(73.7)$ & $392(58.0)$ \\
\hline 2 & $176(26.5)$ & $67(28.3)$ & $19(15.3)$ & $26(7.7)$ & $110(8.7)$ & $211(31.2)$ \\
\hline 3 & $164(24.7)$ & $29(12.2)$ & $35(28.2)$ & $59(17.5)$ & $221(17.6)$ & $73(10.8)$ \\
\hline Total & $664(100)$ & $237(100)$ & $124(100)$ & $337(100)$ & $1259(100)$ & $676(100)$ \\
\hline
\end{tabular}

1. Mucosal Thickening; 2 . Sinusal Opacification; 3. Polypoid Lesions.

Drumond $x$ Raghav: $\chi^{2}=16.74(p=0.002)$.

Drumond $x$ Manji: $\chi^{2}=7.02(p=0.0299)$.

Drumond x Gracco: $\chi^{2}=70.53(p<0.0001)$.

Drumond $x$ Rege: $\chi^{2}=144.8(p<0.0001)$.

Drumond $x$ Ritter: $\chi^{2}=44.46(p<0.0001)$.

have almost double the relative risk of polypoid formations, and even patients aged 41-60 years have a risk of $401 \%$ of developing mucoperiosteal thickening. ${ }^{16}$

\section{Conclusion}

Based on the methods and the sample analyzed, we conclude that: there is a high prevalence of sinus maxillary diseases. Mucosal thickening; acute, chronic, and odontogenic sinusitis; polypoid lesions and tumors are very frequent. A correct diagnosis of odontogenic processes identifying dental cause is essential for successful treatment. It is clear that early diagnosis of cancer favors a better prognosis. Our study found that combined anatomic regions and maxillary sinus floor were the highest occurrence locations. We found that gender and age of patients were not influencing factors nor were right, left side or bilateral involvement. Moreover, the frequency of findings does not vary with statistically significance according to the sex or age of the patients. Finally, facial CT scans were effective in the evaluation of pathological findings in the maxillary sinuses.

\section{References}

1 Ogle OE, Weinstock RJ, Friedman E. Surgical anatomy of the nasal cavity and paranasal sinuses. Oral Maxillofac Surg Clin North Am 2012;24(2):155-166, vii

2 Van Dis ML, Miles DA. Disorders of the maxillary sinus. Dent Clin North Am 1994;38(1):155-166

3 Stephens JC, Saleh HA. Evaluation and treatment of isolated maxillary sinus disease. Curr Opin Otolaryngol Head Neck Surg 2013;21(1):50-57

4 Lawson W, Patel ZM, Lin FY. The development and pathologic process that influence maxillary sinus pneumatization. Anat Rec 2008;291:1154-1163

5 Mehra P, Jeong D. Maxillary sinusitis of odontogenic origin. Curr Allergy Asthma Rep 2009;9(3):238-243

6 White SC, Pharoah MJ. Oral Radiology. 6th ed. St. Louis: Mosby Elsevier; 2009:506-512

7 Brozek JL, Bousquet J, Baena-Cagnani C, et al. Allergic rhinitis and its impact on asthma (ARIA) guidelines: 2010 revision. J Allergy Clin Immunol 2010;126:466-476
8 Tezer MS, Tahamiler R, Canakçioğlu S. Computed tomography findings in chronic rhinosinusitis patients with and without allergy. Asian Pac J Allergy Immunol 2006;24(2-3):123-127

9 Okuyemi KS, Tsue TT. Radiologic imaging in the management of sinusitis. Am Fam Physician 2002;66(10):1882-1886

10 Lana JP, Carneiro PMR, Machado VdeC, de Souza PE, Manzi FR, Horta MCR. Anatomic variations and lesions of the maxillary sinus detected in cone beam computed tomography for dental implants. Clin Oral Implants Res 2012;23(12):1398-1403

11 Mehra P, Murad H. Maxillary sinus disease of odontogenic origin. Otolaryngol Clin North Am 2004;37(2):347-364

12 Kanagalingam J, Bhatia K, Georgalas C, Fokkens W, Miszkiel K, Lund VJ. Maxillary mucosal cyst is not a manifestation of rhinosinusitis: results of a prospective three-dimensional CT study of ophthalmic patients. Laryngoscope 2009;119(1):8-12

13 Almeida WLC, Martin LRL, Perazzo PSL, Anjos CAL, Lima MS. Maxillary Sinus mucopyocele with facial asymmetry. A case report. Int Arch Otorhinolaryngol 2004;8:1-3

14 Katz TS, Mendenhall WM, Morris CG, Amdur RJ, Hinerman RW, Villaret DB. Malignant tumors of the nasal cavity and paranasal sinuses. Head Neck 2002;24(9):821-829

15 Ritter L, Lutz J, Neugebauer J, et al. Prevalence of pathologic findings in the maxillary sinus in cone-beam computerized tomography. Oral Surg Oral Med Oral Pathol Oral Radiol Endod 2011;111(5):634-640

16 Gracco A, Incerti Parenti S, Ioele C, Alessandri Bonetti G, Stellini E. Prevalence of incidental maxillary sinus findings in Italian orthodontic patients: a retrospective cone-beam computed tomography study. Korean J Orthod 2012;42(6):329-334

17 Rege IC, Sousa TO, Leles CR, Mendonça EF. Occurrence of maxillary sinus abnormalities detected by cone beam $\mathrm{CT}$ in asymptomatic patients. BMC Oral Health 2012;12:30

18 Dobele I, Kise L, Apse P, Kragis G, Bigestans A. Radiographic assessment of findings in the maxillary sinus using cone-beam computed tomography. Stomatologija 2013;15(4):119-122

19 Manji A, Faucher J, Resnik RR, Suzuki JB. Prevalence of maxillary sinus pathology in patients considered for sinus augmentation procedures for dental implants. Implant Dent 2013;22(4):428-435

20 Raghav M, Karjodkar FR, Sontakke S, Sansare K. Prevalence of incidental maxillary sinus pathologies in dental patients on conebeam computed tomographic images. Contemp Clin Dent 2014; 5(3):361-365

21 Guerra-Pereira I, Vaz P, Faria-Almeida R, Braga AC, Felino A. CT maxillary sinus evaluation-A retrospective cohort study. Med Oral Patol Oral Cir Bucal 2015;20(4):e419-e426 